\title{
Acoustical Analysis of Road Traffic Density
}

\author{
Miroslav Němec ${ }^{1}$, Tomáš Gergel’2, Jozef Kovalíček ${ }^{1}$, \\ Miloš Gejdoš ${ }^{3 *}$ Zuzana Danihelová ${ }^{4}$ \\ ${ }^{1}$ Technical University in Zvolen, Faculty of Wood Sciences and Technology, Department of Physics, \\ Electrical Engineering and Applied Mechanics, \\ T. G. Masaryka 24, 960 53, Zvolen, Slovakia \\ ${ }^{2}$ Technical University in Zvolen, Faculty of Wood Sciences and Technology, Department of Fire Protection, \\ T. G. Masaryka 24, 960 53, Zvolen, Slovakia \\ ${ }^{3}$ Technical University in Zvolen, Faculty of Forestry, Department of Forest Harvesting, \\ Logistics and Ameliorations, \\ T. G. Masaryka 24, Zvolen, 960 53, Slovakia \\ ${ }^{4}$ Technical University in Zvolen, Institute of Foreign Languages, \\ T. G. Masaryka 24, Zvolen, 960 53, Slovakia
}

Received: 26 February 2016

Accepted: 19 April 2016

\begin{abstract}
Road traffic is one of the most often used means of transportation of people and goods today. Consumerism causes a constant increase in the demand for goods and services. Our paper presents a proposal for traffic monitoring. Its aim was to design a method for measuring traffic density using acoustical methods. It describes the results of measuring traffic density via acoustical methods and their comparison with actual traffic density obtained from video camera records. Traffic density was measured also for individual vehicle categories. Measurement and analysis of audio and video records has shown a correlation between the actual number of vehicles passing by and data about the number of vehicles obtained from the analysis of audio records.
\end{abstract}

Keywords: traffic telematics, acoustics, traffic density, bridge joint

\section{Introduction}

In the European Union two thirds of all goods are transported via roads, and on average two inhabitants are allotted per car. Extensive road traffic requires more and more sophisticated ways of controlling and organising the traffic. The technological progress in vehicle manufacture and economic availability of automobiles, together with building new roads, accelerates transport time significantly and decreases the impact on the environment. However, at the same time it increases the number of cars on the roads and the extent of exposed areas. Due to the expansion of road traffic in the last decades it is inevitable to improve the systems for analysing and controlling road traffic and its impact on the environment. This paper deals with a proposed method for determining the road traffic density based on an audio record [1-2].

*e-mail: gejdos@tuzvo.sk 


\section{Material and Methods}

\section{Current Methods for Road Traffic Density Measurement}

Monitoring traffic and subsequently analysing the various parameters of road traffic are parts of modern and intelligent traffic systems. Information is used in order to improve traffic control and enable the travellers or commuters to reach their destination faster with lower energy consumption. Currently, various systems (e.g., inductive loops under the roads, radar, or video cameras) are used to obtain the necessary data. There are also methods of potential management and planning for further explanation using GIS [3-4]. For the traffic management, methods for transportation engineering are also important [5-6]. However, all these technologies used for monitoring traffic are costly. We have tried to test the possibility of measuring traffic density using acoustic methods, which seem to be less costly [7-9].

However, the overall level of predicted noise can be influenced by various factors; in other words the noise consists of more components that determine the final value. These components can be divided into basic and derived. The basic factors determining noise from road traffic include the influence of operation and vehicle construction and factors connected to the environment and its surroundings. The derived factors cover the factors connected to the method of traffic operations [10-16].

\section{Measurement Location}

The method of analysing the traffic density using audio recordings was proposed in cooperation with the company Betamont, s.r.o., Zvolen, dealing with the technologies for traffic networks and traffic telematics. Within this task the measurement was carried out on two measurement locations. The first was situated on road R1 from Banská Bystrica towards Zvolen, prior to turning toward the housing estate Radvaň, where Betamont has a road measurement unit situated on this spot. The unit records the number and parameters of vehicles passing by. After processing the data from this location we found out that the proposed method is not suitable for application on this location due to traffic occurring in more lanes and its high frequency [9].

The measurements have shown that this measurement location requires a specific sound source connected to vehicles passing in maximum of two lanes. The criterion was met by the second measurement location at road number 50 at the entry to Zvolen (approx. $500 \mathrm{~m}$ from the traffic sign of the town Zvolen) where the measurement was carried out. This location features two-way traffic with a maximum speed limit of $90 \mathrm{~km} / \mathrm{h}$. This location is provided with a flyover over the road with a bridge dilatation joint, which served as a source of specific sound for the measurement.

Measurement was carried out on 19 March 2015 between 10:00 and 14:00. Four audio recordings with four synchronous video recordings were made for the evaluation of the type and number of cars passing by. During the whole measurement the weather was stable (mainly clear or partly cloudy), and the temperature varied between $8^{\circ} \mathrm{C}$ (at the beginning of the measurement) and $13^{\circ} \mathrm{C}$ (at the end of the measurement). Atmospheric humidity was $45 \%$ and wind speed reached a maximum $5 \mathrm{~km} / \mathrm{h}$. The weather conditions during the measurement were satisfactory for accurate measuring performance of the sound level meter [17]. We used a Brüel \& Kjaer 2270 sound-level meter, a Brüel\&Kjaer 4231 sound calibrator, a video camera, and UPS during the measurement.

\section{Bridge Dilatation Joint}

A bridge joint is used to bridge the dilatation gap between bridge construction and bridge support, between two pieces of load-bearing bridge construction, or between load-bearing bridge construction and an adjacent road (Fig. 1). The main function of a bridge joint is to enable the dilatation movement of load-bearing construction in accordance with the selected bridge structural system. One of the technological requirements on the bridge joints according to the "Technological and Qualitative Requirements of the Ministry of Transport, Constructions and Reginal Development of the Slovak Republic (2013), part 24: bridge joints" is that a bridge joint has to provide for the required noise emissions when cars cross the joint. The noisiness of the bridge joint is caused probably by its wear or other defect. The bridge joint (Fig. 1) was the source of specific sound that was used while designing the method for traffic density determination $[1,18]$. Currently, the bridge has been reconstructed and the new bridge joint does not show excessive noisiness.

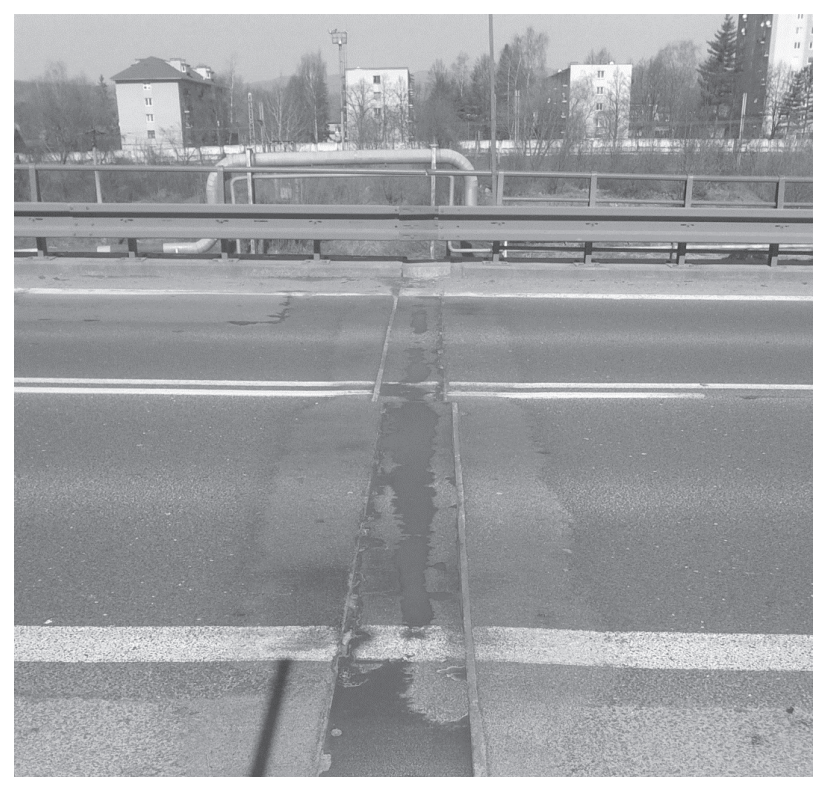

Fig. 1. Bridge joint - a source of specific sound. 
Table 1. Filter setting (all values are in $\mathrm{dB}$ ).

\begin{tabular}{|l|l|l|l|l|l|l|l|l|l|}
\hline \multicolumn{2}{|c|}{ Cars } & \multicolumn{3}{c|}{ Lorries } & \multicolumn{3}{c|}{ Articulated vehicles } & \multicolumn{3}{c|}{ All vehicles } \\
\hline $\mathrm{L}_{\text {Aeq }} \geq 82.5$ & $\mathrm{~L}_{\text {Cpeak }} \leq 110$ & $\mathrm{~L}_{\text {Aeq }} \geq 82.5$ & $\mathrm{~L}_{\text {Cpeak }} \geq 113$ & $\mathrm{~L}_{\text {Aeq }} \geq 82.5$ & $\mathrm{~L}_{\text {Cpeak }} \geq 115$ & $\mathrm{~L}_{\text {Aeq }} \geq 82.5$ & $\mathrm{~L}_{\text {Cpeak }} \geq 100$ \\
\hline
\end{tabular}

\section{Results}

The whole measurement was recorded continuously using a video camera and sound level meter. During the evaluation of data the audio and video recordings were synchronised using synchronising symbols. Data stored in the sound level meter can be analysed only by software provided by the device manufacturer (BZ-5503 Measurement Partner Suite). Data for further processing were imported from the programme to the MS Excel spreadsheet. The aim of the measurement was to determine the number of vehicles passing by based on the sound created when crossing the bridge dilatation joint. When analysing the measured data we anticipated the existence of the minimum value $L_{\text {Aeq }}$ and $L_{\text {Cpeak }}$ created by a vehicle crossing the bridge joint in both directions. The crossing vehicle caused significant sound created by the impact of metal parts of the joint. This sound could have been clearly distinguished from the background sound through its significantly higher values of $L_{\text {Aeq }}$ and $L_{\text {Cpeak }}$. The minimal value of sound pressure created by the automobile crossing the joint was determined using the graphical outputs and statistical functions of the programme Measurement Partner Suite. Statistical value $\mathrm{L}_{\mathrm{AF} 30}$ were used to find out the minimum value of sound pressure. This value is not listed among the basic statistical descriptors; however, it can be derived easily. It was selected with the first statistical set and subsequently it was applied on further sets, whereby this selection was proven as suitable. The value $\mathrm{L}_{\mathrm{AF} 30}$ gives the probability level of sound pressure, which is exceeded $30 \%$ of the time from the given time interval. A similar procedure also was followed when determining the remaining filters for individual vehicle categories. The minimum value of sound pressure $L_{\mathrm{AF} 30}$ was determined at $82.5 \mathrm{~dB}$. This means that $30 \%$ of the recorded one-second recordings of sound pressure exceeds this value. All one-
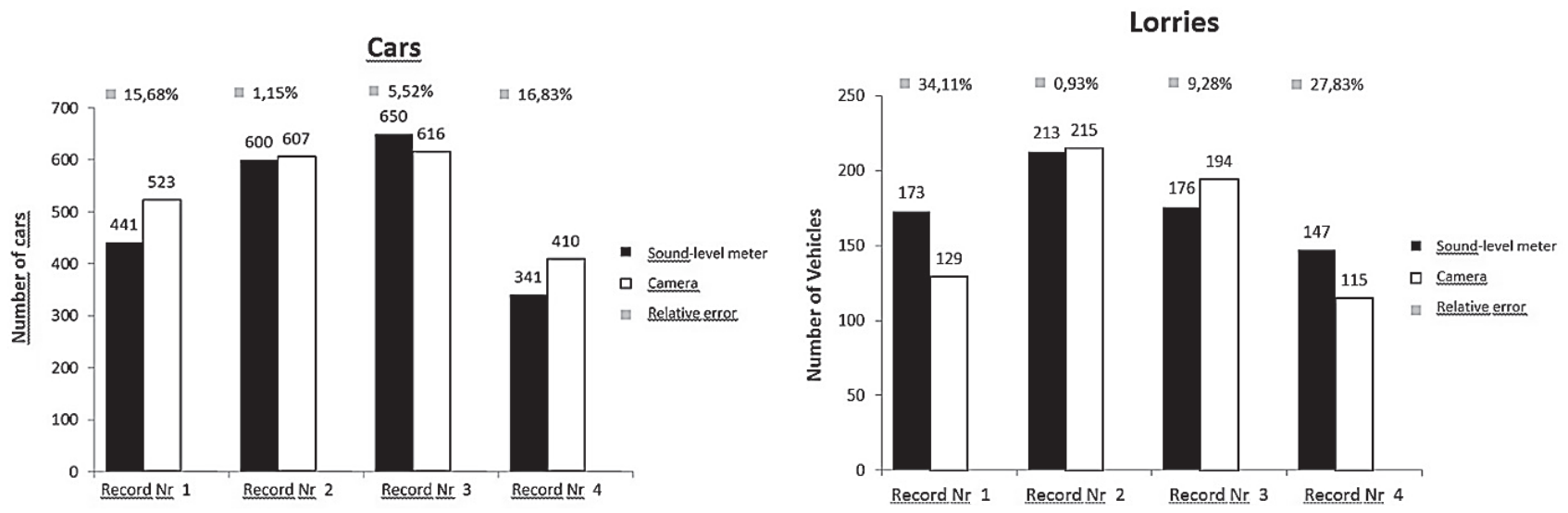

Fig. 2. Comparison of the number of cars and lorries obtained from the video and audio recordings.
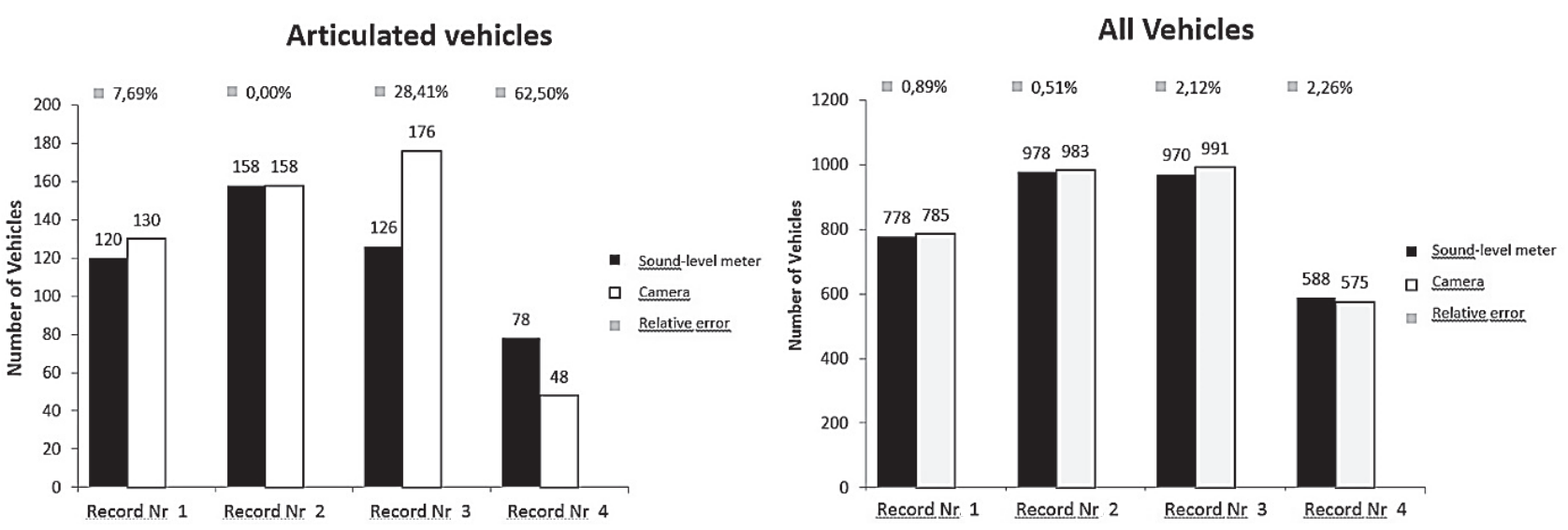

Fig. 3. Comparison of the number of articulated vehicles and all vehicles obtained from the video and audio recordings. 


\section{Overall mean relative error for whole measurement time}

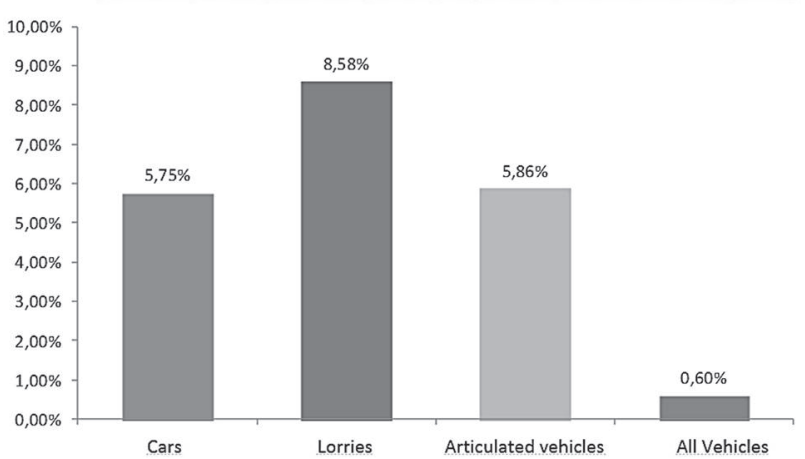

Fig. 4. Mean relative error in measurement during the entire measurement time for individual vehicle categories and all vehicles.

second recordings with a sound pressure value higher than $82.5 \mathrm{~dB}$ are values of vehicles passing by, since there was no other significant source of sound present during the measurement. Synchronising the video and sound recordings allowed us to identify the vehicle category and corresponding value of sound pressure. This way all filters for every vehicle category were set according to Table 1.

The bar charts (Figs 2 and 3) show the evaluation of absolute numbers of vehicles in individual categories determined according to the video as well as audio recordings. The charts also include the relative error in measurement done by the sound level meter. The relative error in measurement was calculated according to the equation:

$$
\delta y=\frac{\Delta y}{Y} .100(\%)
$$

...where $\delta y$ is relative error in measurement (\%), $\Delta y$ is absolute error in measurement (the difference between the real number of vehicles and the number of vehicles determined by the audio record), and $Y$ is the real number of vehicles.

Fig. 4 illustrates the mean relative error in measurement concerning the entire measurement time. The bars of the chart show the mean relative error for all vehicles as well as for individual vehicle categories.

\section{Discussion}

Following the data illustrated in the charts, we can conclude that the method is relatively accurate for recording the number of all vehicles passing by (relative error $0.6 \%$ ). Greater deviation can be observed when determining the individual categories of vehicles passing by. The greatest deviation in the number of vehicles was recorded with lorries (relative error $8.58 \%$ ). The error probably is caused by vehicle and cargo weight. In the case of articulated vehicles (relative error 5.86\%) the major factor causing inaccuracy is the number of axles and extent of vehicle utilisation; the crossing time is sometimes more than one second, therefore the vehicle is counted twice. The lowest deviation was recorded in the category of cars (relative error $5.75 \%$ ).

A slight inaccuracy in the overall number of vehicles passing by could have been caused by multiple cars crossing the bridge joint at the same time in both lanes, causing blending of the sound from the bridge joint and distorting the measurement results.

\section{Conclusion}

In order to make the measurement method more accurate, we propose locating the specific sound sources for individual lanes independently at least $100 \mathrm{~m}$ from each other. Measurement and analysis of audio and video recordings has shown a correlation between the actual number of vehicles passing by and data about the number of vehicles obtained from the recordings. Further research will provide more exact results and will allow us to determine more parameters.

The improvement of the method parallels the development of a simple acoustic sensor with incorporated evaluation software used for measuring road traffic density. Moreover, the incorporated software will be much cheaper than the camera systems, while the range of evaluated data and the possibility of their utilisation depend on the implemented software features and not on the measuring apparatus. A mobile device that could be used as a source of specific noise is being developed.

\section{Acknowledgements}

The research described in this paper was financed jointly by the KEGA (Project No. 003TU Z-4/2015) and OP R\&D ITMS 26220220169.

\section{References}

1. KOVALÍČEK J. Propose methods for determining the density of traffic and noise assessment load. Diploma thesis, 2015.

2. BARTOŠOVÁ L. Transport and its impact on environment damage. Transport in urban units. 257, 1999.

3. CETIN M. Consideration of permeable pavement in landscape architecture. J. Environ. Prot. Ecol. 16 (1), 385, ISSN 1311-5065, 2015.

4. CETIN M. Using GIS analysis to assess urban green space in terms of accessibility: case study in Kutahya. Int. J. Sust. Dev. World 22 (5), 420, ISSN 1745-2627, 2015.

5. BROOKS R., CETIN M. Influence of vehicles weight ratio on the initial velocity of vehicle in chain accidents at intersections. IJRRAS 17 (2), 212, ISSN: 2349-4891, 2013.

6. BROOKS R., CETIN M. Application of construction demolition waste for improving performance of subgrade and subbase layers. IJRRAS 12 (3), 375, ISSN: 2349-4891, 2012. 
7. DADO, M., HNILICA, R., SCHWARZ, M. Modelling of noise generated by woodworking machinery with respect to occupational noise exposure. Inter-Noise 2013: Noise Control for Quality of Life 42, (1), 6098, 2013.

8. HOCKICKO P. High frequency acoustic spectroscopy of perspective materials for electrotechnics. Akustika: odborný časopis o akustice a vibracích. 17 (1), 10, ISSN 1801-9064, 2012.

9. NĚMEC M., GERGEL' T., KOVALÍČEK J., GEJDOŠ, M., DANIHELOVÁ Z. Acoustical analysis of road traffic. Akustika: odborný časopis o akustice a vibracích. 23, (1), 10, ISSN 1801-9064, 2015

10. ZAGUBIEŃ, A., WOLNIEWICZ, K., Verifying Traffic Noise Analysis Calculation Models. Pol. J. Environ. Stud. 24 (6), $2767,2015$.

11. EHRAMPOUSH M.H., HALVANI G.H., BARKHORDARI A., ZARE M. Noise Pollution in Urban Environments: a Study in Yazd City, Iran. Pol. J. Environ. Stud. 21 (4), 1095, 2012.

12. NĚMEC M., DANIHELOVÁ A., GEJDOŠ M., GERGEL' T., DANIHELOVÁ Z., SUCHOMEL J., ČULÍK M. Train Noise - Comparison of Prediction Methods. Acta Physica Polonica A. 127 (1), 125, 2015.
13. SCHAUFELBERGER W., MOOS M. Systems and methods for detecting traffic data and automatic recognition of events. Telema. 1, CZ, 2004.

14. GNAP J., NOGA M. Influence of the traffic flow composition on the traffic noise in cities. Doprava a spoje. 2012 (1), 93, ISSN 1336-7676, 2012.

15. LAZAROVÁ P., KLUKNAVSKÁ Z. Prediction of traffic intensity in the assessment of noise from the road. Proceedings of the International Conference, Žilina: Strix, edition ESE. 11 (1), 185, ISBN 978-80-89281-84-8, 2012.

16. DANIHELOVÁ A., ZACHAR M., RYBAKOWSKI M., DUDARSKI G. Noise and vibrations - important factors influencing the working performance and human health. New trends of acoustic spectrum: Scientific peer-reviewed Proceedings. Zvolen. 197. ISBN 978-80-228-2647-1. 2014.

17. STN ISO 1996-2 Acoustics. Description, measurement and assessment of environmental noise. Part 2: Determination of environmental noise levels. SK, 2008.

18. BRLIŤ F. Technical and qualitative conditions. Part 24 Bridge Expansion Joint. TKP. SK, 2006. 